EPSC Abstracts

Vol. 14, EPSC2020-637, 2020, updated on 08 Nov 2020

https://doi.org/10.5194/epsc2020-637

Europlanet Science Congress 2020

(C) Author(s) 2020. This work is distributed under

the Creative Commons Attribution 4.0 License.

\title{
Hunting for Methane on Mars: one Martian year of survey with ACS on TGO
}

Franck Montmessin ${ }^{1}$, Oleg Korablev ${ }^{2}$, Anna A. Fedorova ${ }^{2}$, Alexander V. Trokhimovskiy ${ }^{2}$, Franck Lefevre $^{1}$, Lucio Baggio ${ }^{1}$, Denis A. Belyaev ${ }^{2}$, Kevin Olsen ${ }^{3}$, Juan Alday ${ }^{3}$, Abdenour Irbah ${ }^{1}$, Gaetan Lacombe $^{1}$, Andrey Patrakeev ${ }^{2}$, Lucas Teinturier ${ }^{1,5}$, Nikolay Ignatiev ${ }^{2}$, Mikhail Luginin ${ }^{2}$, Alexey Shakun ${ }^{2}$, Sandrine Guerlet ${ }^{4}$, François Forget ${ }^{4}$, Ehouarn Millour ${ }^{4}$, and Colin F. Wilson ${ }^{3}$

${ }^{1}$ CNRS/IPSL/UVSQ/UPMC, LATMOS, Guyancourt, France (franck.montmessin@latmos.ipsl.fr)

${ }^{2}$ Space Science Institute, IKI, Moscow, Russian Federation

${ }^{3}$ Physics Department, Oxford University, Oxford, United Kingdom

${ }^{4}$ LMD CNRS Jussieu, Paris, France

${ }^{5}$ now at Mc Gill University, Montreal, Canada

\begin{abstract}
The Atmospheric Chemistry Suite (ACS) [1], one of the four science experiments on board ESARoscosmos ExoMars 2016 Trace Gas Orbiter (TGO) mission has started science operations in March 2018. ACS consists of 3 infrared spectrometers targeting the unambiguous detection of trace gases of potential geophysical or biological interest. The dataset reported here concerns the methane detection attempts conducted during the first complete Martian year (almost two Earth years) of observations using ultra-sensitive occultation observing mode in orbit around Mars.
\end{abstract}

The Trace Gas Orbiter (TGO) of the ESA-Roscosmos ExoMars mission has ended its trip to Mars, reaching the planet in October 2016. After a year-long aerobraking phase, its scientific mission has begun on April 22 $2^{\text {nd }}, 2018$ with the execution of the first solar occultation. The primary objective of TGO is to detect, map and locate trace gas sources, possibly revealing a residual geophysical (or even biological) activity on Mars. The instrument of interest here is the infrared spectrometer Atmospheric Chemistry Suite (ACS). ACS covers a wavelength range from 0.7 to $17 \mu \mathrm{m}$ at very high spectral resolution ( $\lambda / \Delta \lambda$ from 5,000 to 50,000$)$. ACS operates in nadir and solar occultation. Its performances complete the TGO trace gas detection arsenal together with NOMAD, the other infrared sounder of TGO.

A large part of the first months of the ACS observing mission has enabled the sensitive search of gaseous methane over a substantial fraction of the Martian globe. The results from the first occultation up until early September 2018 will be presented. This period incidentally covered the onset, the full development, and the demise of the Planetary Encircling Dust Event observed by several other instruments orbiting currently around Mars. Observing conditions proved more favourable than anticipated, and it was possible in a few cases to probe the Martian atmosphere close to the surface $(<5 \mathrm{~km})$ where the MSL Curiosity rover has established the existence of a seasonally varying background level of $\mathrm{CH} 4$ concentrations ranging between 240 and 650 pptv [2]. 


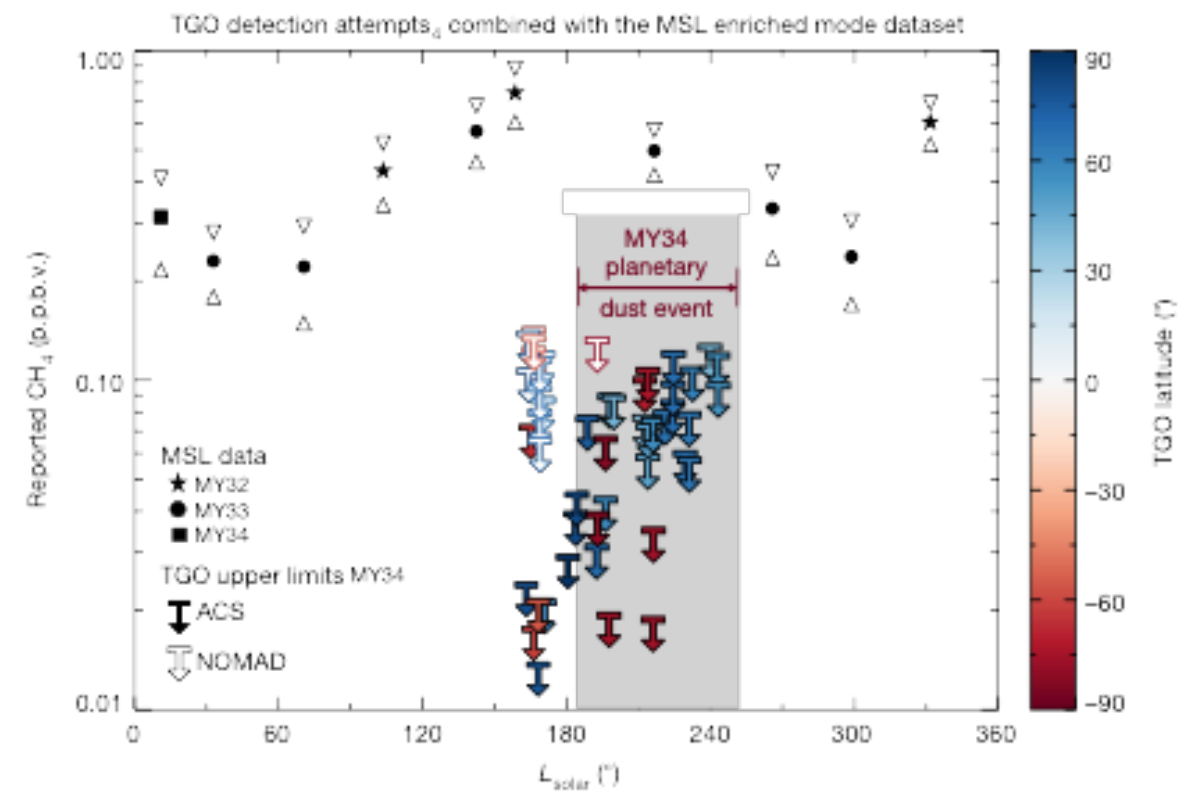

The first five months of ACS $\mathrm{CH} 4$ detection attempts were reported in [3], revealing the absence of methane detection over most of the Martian globe (Figure 1). Part of the attempts at that time was impaired by the presence of abundant amounts of dust particles that prevent observing the lower troposphere of Mars $(<30 \mathrm{~km}$ ) where methane, if detectable, presumably concentrates.

The ACS dataset analyzed here covers a period of more than 25 months, which is five times more data (Figure 2) than previously analyzed. This gives us a chance to perform a deeper exploration into the potential presence of methane and the consequences it may have for our understanding of active geophysical and physicochemical processes prevailing at Mars.
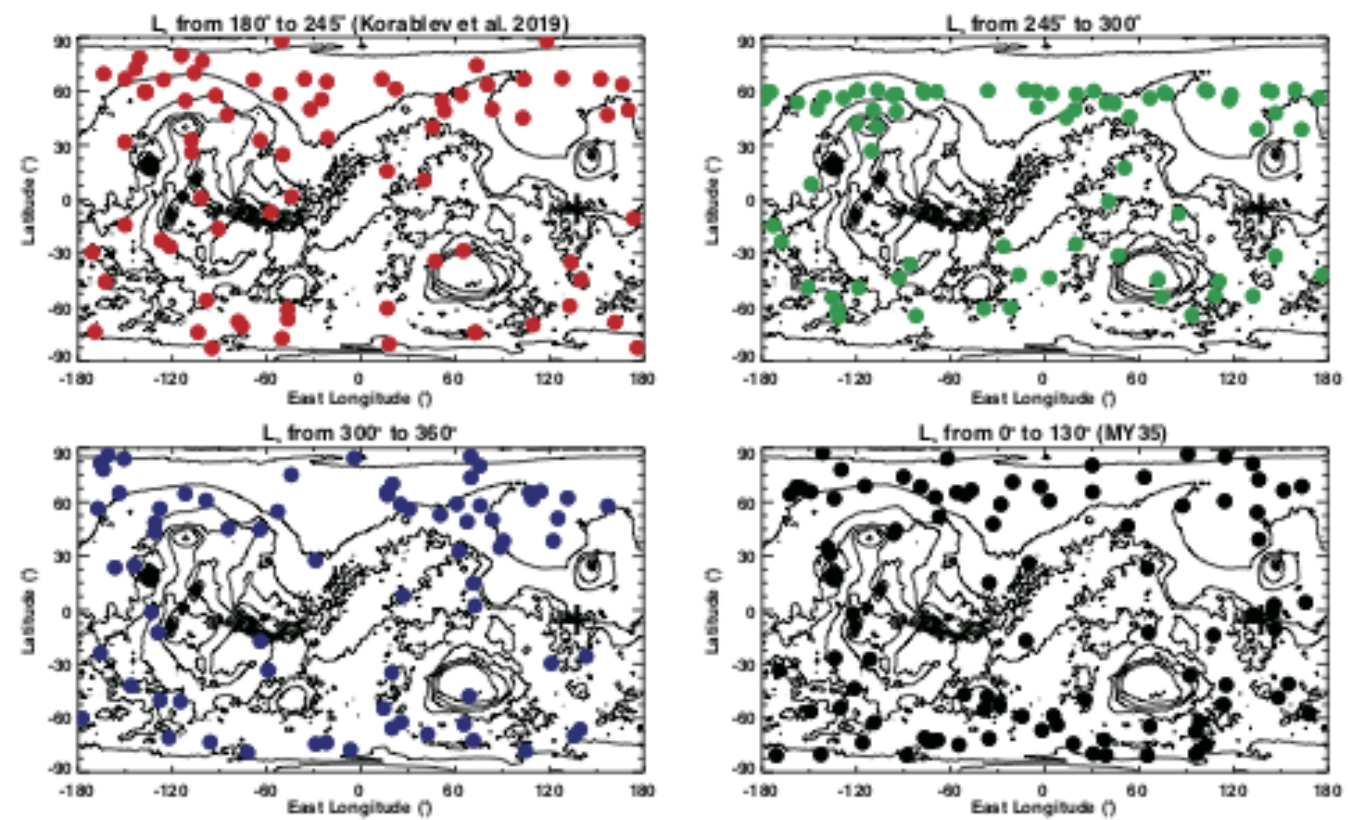